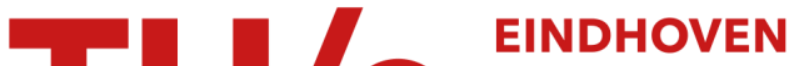 \\ UNIVERSITY OF \\ TECHNOLOGY
}

\section{Controlled Radical Polymerization in Emulsion}

Citation for published version (APA):

Bon, S. A. F., Bosveld, M., Klumperman, B., \& German, A. L. (1997). Controlled Radical Polymerization in Emulsion. Macromolecules, 30(2), 324-326. https://doi.org/10.1021/ma961003s

DOI:

10.1021/ma961003s

Document status and date:

Published: 01/01/1997

\section{Document Version:}

Publisher's PDF, also known as Version of Record (includes final page, issue and volume numbers)

\section{Please check the document version of this publication:}

-A submitted manuscript is the version of the article upon submission and before peer-review. There can be important differences between the submitted version and the official published version of record. People interested in the research are advised to contact the author for the final version of the publication, or visit the $\mathrm{DOI}$ to the publisher's website.

- The final author version and the galley proof are versions of the publication after peer review.

- The final published version features the final layout of the paper including the volume, issue and page numbers.

Link to publication

\section{General rights}

Copyright and moral rights for the publications made accessible in the public portal are retained by the authors and/or other copyright owners and it is a condition of accessing publications that users recognise and abide by the legal requirements associated with these rights.

- Users may download and print one copy of any publication from the public portal for the purpose of private study or research.

- You may not further distribute the material or use it for any profit-making activity or commercial gain

- You may freely distribute the URL identifying the publication in the public portal.

If the publication is distributed under the terms of Article $25 \mathrm{fa}$ of the Dutch Copyright Act, indicated by the "Taverne" license above, please follow below link for the End User Agreement:

www.tue.nl/taverne

\section{Take down policy}

If you believe that this document breaches copyright please contact us at:

openaccess@tue.nl

providing details and we will investigate your claim. 


\section{Communications to the Editor}

\section{Controlled Radical Polymerization in Emulsion}

\section{Stefan A. F. Bon, Michiel Bosveld, Bert Klumperman,* and Anton L. German}

Laboratory of Polymer Chemistry, Eindhoven Polymer Laboratories (EPL), E indhoven University of Technology, P.O. Box 513, 5600 MB Eindhoven, The Netherlands

Received J uly 11, 1996

Revised Manuscript Received November 13, 1996

The understanding and development of theoretical descriptions of an emulsion polymerization is complex because of the heterogeneity of the system. Mechanistic models have been developed in order to give us some control of the molar mass distribution (MMD) and the configurational and compositional sequences during the polymerization process.1,2 The molecular weight distribution of the polymer synthesized in an emulsion polymerization process can be controlled by influencing the entry and exit coefficients and chain-stopping reactions by means of varying initiator concentration, number of particles, and particle size distribution or by means of addition of a chain-transfer agent.

A novel radical polymerization method that is able to control the MMD and has received considerable attention recently is the control led radical polymerization. ${ }^{3,4}$ This process differs from the conventional free radical polymerization in that an additional specific compound is added which is capable of reversible homoIytic dissociation and/or transfer. By these means, it is able to control all or part of the events that take place in the polymerizing reaction mixture. The compound used in our case is the alkoxyamine 1-tert-butoxy-2phenyl-2-(1-oxy-2,2,6,6-tetramethylpiperidinyl)ethane (1) ${ }^{5}$ (see Scheme 1). In the ideal case, that is, a truly living radical polymerization, permanent chain stoppage of the polymeric radical is prevented by exclusion of both bimolecular termination and transfer reactions.

The controlled radical polymerization technique applied in a heterogeneous system could be a valuable tool to control both the molar mass distribution and the chemical composition distribution of the polymer. ${ }^{6}$ In this report, preliminary results of applying the controlled radical polymerization technique in emulsion polymerization of styrene are reported.

In order to study the effect of the addition of the alkoxyamine on the molar mass distribution of an emulsion polymerization of styrene, the latex produced must have a uniform particle size distribution. A short particle formation period and the absence of coagulation during the stage of particle growth are required to rule out broadening of the molar mass distribution during the polymerization caused by a nonuniformity in the loci of polymerization.

The particle formation is a complex process, especially in systems where the concentration of added surfactant is above the critical micelle concentration and the initiating radical species have a low water solubility. Attempts to prepare a stable latex via spontaneous thermal initiation of the monomer, in the present case styrene, require the addition of high amounts of surfactant to decrease the amount of monomer droplets and to stabilize the particles formed. In this case, however, the stage of particle formation will continue throughout the major part of the polymerization process. Due to the above considerations, the task to ab initio synthesize a monodisperse latex under these conditions appears to be impossible. To avoid the complexities of nucleation, the present study is restricted to seeded emulsion polymerization systems.

The recipe for the polystyrene seed latex is presented in Table 1. The experiment was carried out under argon in a jacketed all-glass reactor, thermostated at $90 \pm 0.5$ ${ }^{\circ} \mathrm{C}$ and equipped with a mechanical six-bladed turbine stirrer. The stirring speed was kept at $250 \mathrm{rpm}$. Before polymerization, the reaction mixture was degassed and purged with argon three times. The polymerization was stopped after $12 \mathrm{~h}$ and the product was filtered through a filter paper. The obtained latex was purified by dialysis at ambient temperature.

The average particle sizes and the polydispersity of the obtained latexes were determined with dynamic light scattering (DLS) and transmission electron microscopy (TEM) (seed latex: $D_{n}=90 \mathrm{~nm}, P D=1.1$ ).

The recipes (i.e. CRP1, CRP2, CRP3a/b/c, and REF) for the seeded emulsion polymerizations that were carried out are presented in Table 2. The seeded emulsion polymerizations were carried out in a Teflonjacketed high-pressure reactor $(0.25 \mathrm{~L})$ under an argon atmosphere of $15 \mathrm{bar}$, thermostated at $125 \pm 0.5^{\circ} \mathrm{C}$ and equipped with a magnetic stirrer. The stirring speed was kept at $350 \mathrm{rpm}$. Prior to the polymerizations, all components were added to the seed latex in a laboratory bottle $(0.5 \mathrm{~L})$ and this was purged with argon. After the bottle had been sealed, the seed latex was allowed to swell for $24 \mathrm{~h}$ while shaking at ambient temperature. Then the reaction mixture was poured into the reactor, degassed, and purged with argon three times.

TEM analysis of the latexes obtained under seeded conditions confirmed the absence of possible secondary nucleation and/or coagulation in the seeded experiments.

In order to analyze the molar mass distribution of the polymer produced with GPC, $0.1 \mathrm{w} / \mathrm{v} \%$ solutions in tetrahydrofuran (THF, stabilized, Biosolve, AR) were prepared of each sample which was isolated by freezedrying.

The solutions were filtrated through $0.2 \mu \mathrm{m}$ syringe filters. The GPC analyses were carried out with two Shodex KF-80M (linear) columns at $40{ }^{\circ} \mathrm{C}$. The eluent was THF at a flow rate of $1 \mathrm{~mL} \cdot \mathrm{min}^{-1}$. A Waters 410 differential refractometer and a Waters 440 UV detector (254 nm) were used for the detection. Narrow-distribution polystyrene standards (Polymer Labs) with molecular weights $(\mathrm{M})$ ranging from 580 to $6.5 \times 10^{6}$ were used for calibration of the columns. After a baseline correction, the GPC chromatograms were converted to a differential log molar mass distribution $(w(\log M)$ vs $\log$ M) according to the procedure described by Shortt. ${ }^{7}$ 
Scheme 1. Reversible Homolytic Dissociation of an Alkoxyamine

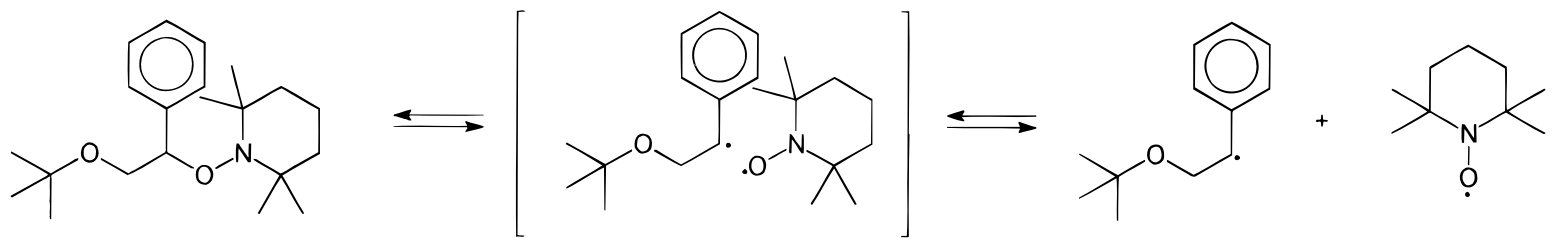

(1)

TEMPO

Table 1. Recipe for the Seed Latex Preparation

\begin{tabular}{ll}
\hline component & \multicolumn{1}{c}{ amount } \\
\hline styrene & $75.14 \mathrm{~g}$ \\
water & $0.156 \mathrm{~L}$ \\
Aerosol MA-80 & $2.681 \mathrm{~g}$ \\
$\mathrm{NaHCO}_{3}$ & $3.00 \mathrm{mmol} \cdot \mathrm{L}^{-1} \mathrm{a}$ \\
$\mathrm{ACVA}$ & $0.90 \mathrm{mmol} \cdot \mathrm{L}^{-1} \mathrm{a}$ \\
DMEA & $2.00 \mathrm{mmol} \cdot \mathrm{L}^{-1} \mathrm{a}$ \\
water & $0.010 \mathrm{~L}$
\end{tabular}

a Concentration is based on the volume of the total amount of water used at room temperature. ACVA $=4,4^{\prime}$-azobis(4-cyanovaleric acid); DMEA = N,N-dimethylethanolamine.

Table 2. Recipes for the Seeded Emulsion Polymerizations

\begin{tabular}{lll}
\hline & \multicolumn{2}{c}{ experiment } \\
\cline { 2 - 3 } & CRP & REF \\
\hline styrene $(\mathrm{g})$ & 11.68 & 11.40 \\
seed $(\mathrm{g})$ & 12.53 & 12.50 \\
alkoxyamine $(\mathbf{1})(\mathrm{g})$ & 0.251 & \\
TEMPO $^{\mathrm{a}}(\mathrm{g})$ & 0.0026 & \\
water $\mathrm{g})$ & 129.4 & 132.4 \\
NaHCO $_{3}(\mathrm{~g})$ & 0.179 & 0.182 \\
Aerosol MA-80 $(\mathrm{g})$ & 1.671 & 1.539 \\
overall reaction time $(\mathrm{h})$ & $\mathrm{x}^{\mathrm{b}}$ & 60
\end{tabular}

a TEMPO was added in order to establish a pseudostate equilibrium. ${ }^{b}$ The total reaction time was varied: CRP1, $60 \mathrm{~h}$; CRP2, 90 h; CRP3a, 12 h; CRP3b, 24 h; CRP3c, 36 h.

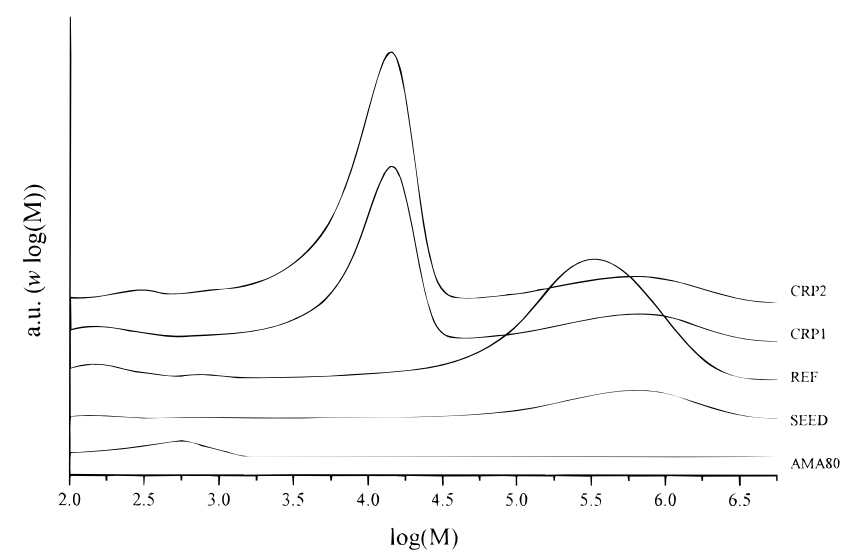

Figure 1. Differential $\log M M D s(w(\log M)$ vs $\log M)$ obtained from the refractometric GPC spectra of the seed latex, the seeded experiments (CRP1, CRP2, and REF), and the surfactant Aerosol MA-80.

In Figure 1, the differential log molar mass distributions obtained from the refractometric GPC spectra of the seed latex, the seeded experiments (CRP1, CRP2(duplo), and REF), and the surfactant Aerosol MA-80 are depicted. (Note that the UV detection showed identical MMDs compared to the refractive index data and, therefore, were not plotted.) As can be observed from these plots, the obtained molar mass distribution of the seeded spontaneous polymerization differs from the experiments in which the alkoxyamine (1) was added. In the latter cases, it is clear that the average

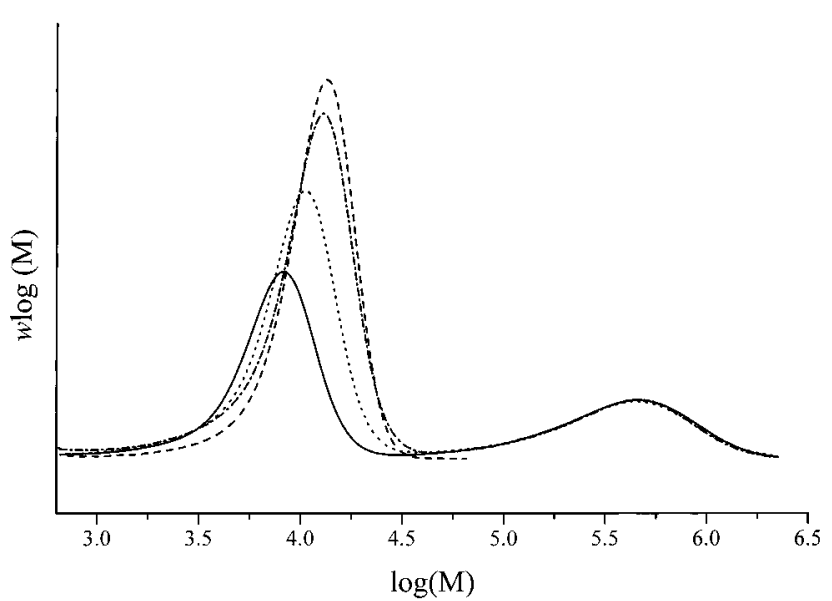

Figure 2. Differential log MMDs obtained from the refractometric GPC spectra of latexes from the CRP3 seeded experiments at different overall reaction times and, therefore, at different stages of monomer conversion (i.e. CRP3a, CRP3b, and CRP $3 c$ ). The overall reaction times of 12,24 , and $36 \mathrm{~h}$ correspond with overall conversions of $0.65,0.80$, and $>0.99$ (respectively -, ..., and - - -). As a comparison, the differential log MMD of a bulk experiment (i.e. BULK) is given (---).

Table 3. Average Molecular Weights and Polydispersity for both the Seeded Controlled Radical Polymerizations of Styrene in Emulsion and a Comparable System in Bulk

\begin{tabular}{lrrrr}
\hline & CRP3a & \multicolumn{1}{c}{ CRP3b } & \multicolumn{1}{c}{ CRP3c } \\
& $12 \mathrm{~h}^{\mathrm{a}}$ & $24 \mathrm{~h}^{\mathrm{a}}$ & $36 \mathrm{~h}^{\mathrm{a}}$ & BULK \\
\hline $\mathrm{M}^{\text {theor } \mathrm{b}} \times 10^{-3}$ & 10.35 & 12.52 & 15.98 & 13.08 \\
$\mathrm{M}_{\mathrm{n}} \times 10^{-3}$ & 5.64 & 6.80 & 7.59 & 9.12 \\
$\mathrm{M}_{\mathrm{w}} \times 10^{-3}$ & 7.96 & 9.87 & 11.64 & 12.56 \\
$\mathrm{M}^{\text {top } \mathrm{c}} \times 10^{-3}$ & 8.13 & 10.55 & 12.90 & 13.33 \\
$\gamma$ & 1.41 & 1.45 & 1.54 & 1.39
\end{tabular}

a Overall reaction time. ${ }^{b} M^{\text {theor }}$ is the theoretical value of the molecular weight, which can be obtained in a living polymerization under recipe conditions at the specific monomer conversion. ${ }^{c} \mathrm{M}$ top is the maximum value of the $w(\log M)$ distribution as represented in Figure 2.

molecular weights are reduced and the MMD narrows.

In Figure 2, the molar mass distributions of the latexes at different overall reaction times and, therefore, at different stages of monomer conversion are presented. The overall reaction times of 12,24 , and $36 \mathrm{~h}$ (respectively CRP3a, CRP3b, and CRP3c) correspond with overall conversions of $0.65,0.80$, and $>0.99$. In Table 3 , the theoretical molecular weights, the average molecular weights, and the polydispersities of the polymer material produced under seeded conditions are given (calculations on the GPC data are performed from 3.0 $\times 10^{4}$ to 580 without subtraction of the polymer seed material). In order to compare these results with a controlled radical polymerization carried out in bulk, the differential log MMD of such an experiment performed under comparable conditions (i.e. $\mathrm{T}=120^{\circ} \mathrm{C} ; \mathrm{p}$ $=1$ bar; $[\mathbf{1}]=5 \times 10^{-2} \mathrm{~mol} \cdot \mathrm{L}^{-1}$; conversion $=0.70$ ) is given (i.e. BULK). 
Both the shape and the polydispersity of the molar mass distributions in the cases where the al koxyamine was added indicate that the polymerization occurs in a similar manner compared to the controlled radical polymerization in a homogeneous polymerization system. ${ }^{5}$ However, as can be observed from these results, the MMDs show a pronounced broadening to low molecular weights and the average molecular weights obtained have lower values than the theoretical ones. This is contributed to a higher amount of chain-stopping reactions (i.e. permanent bimolecular termination and/ or transfer) caused by both the heterogeneity of the system (e.g. partitioning and compartmentalization) and a possible increase in the additional radical flux (caused by a source other than the homolytic dissociation of the alkoxyamine). The latter is caused by an enhancement of the thermal Diels-Alder reaction of styrene in the current system compared to a system in bulk.5,8 The increase in rate of the Diels-Alder reaction could be due to so-called hydrophobic effects (i.e. the tendency of nonpolar species to aggregate in aqeuous solution, so as to decrease the hydrocarbon-water interfacial area), which influence rates and selectivities, if nonpolar segments of the reactants are brought together in the transition state. ${ }^{9}$

The resulting additional flux of radicals causes bimolecular termination and the formation of novel low molecular weight alkoxyamines, resulting in a broadening to the low molecular weight side of the MMD.

It should be noted that prolonged reaction times after complete conversion has been reached result in a broadening of the MMD. This can be ascribed to the instability of the alkoxyamine bond.
It can be concluded that the current drawbacks of the controlled radical polymerization in emulsion of styrene are the higher amount of chain-stopping reactions and that $a b$ initio experiments are ruled out by nonaqueous phase initiation. Moreover, the elevated temperatures restrict the application to those monomers that are not susceptible to hydrolysis. In order to overcome these problems and to apply the controlled radical polymerization as a method to control the molar mass distribution in emulsion polymerizations, a system needs to be developed that operates at ambient temperatures.

\section{References and Notes}

(1) Clay, P. A.; Gilbert, R. G. Macromolecules 1995, 28, 552.

(2) Schoonbrood, H. A. S. Ph. D. Thesis, Eindhoven University of Technology, 1994.

(3) Georges, M. K.; Veregin, R. P. N.; Kazmaier, P. M.; Hamer, G. K. Trends Polym. Sci. 1994, 2 (2), 66.

(4) Solomon, D. H.; Rizzardo, E.; Cacioli, P. U.S. Patent 4,581,429, 1985; Chem. Abstr. 1985, 102, 221335q

(5) Bon, S. A. F.; Bergman, F. A. C.; Chambard, G.; Klumperman, B.; German, A. L., in preparation.

(6) The control of the chemical composition distribution in a heterogeneous system has not been reported in the literature to our knowledge. Gradient copolymers of MMA/MA and Sty/MA have been prepared in a homogeneous system via atom transfer radical polymerization by Matyjaszewski et al. (Greszta, D.; Matyjaszewski, K. Polym. Prepr. 1996, 37 (1), 569).

(7) Shortt, D. W. J . Liquid Chromatogr. 1993, 16, 3371.

(8) Mayo, F. R. J . Am. Chem. Soc. 1968, 90, 1289. Buzanowski, W. C.; Graham, J . D.; Priddy, D. B.; Shero, E. Polymer 1992, 33, 3055. Moad, G.; Rizzardo, E.; Solomon, D. H. Polym. Bull. 1982, 6, 589.

(9) Breslow, R. Acc. Chem. Res. 1991, 24 (6), 159. 